\title{
A few reflexions about an ethnocentric discourse in the context of international tourism
}

\author{
M. C. A. Pavez \\ Universidade Católica de Brasília, Brazil
}

\begin{abstract}
This was a qualitative study that addressed an ethnocentric discourse in the context of international tourism based on the narrative of three tourists after their travels abroad. Ethnocentrism as a central or peripheral issue gave insights to several areas of study, but, apparently, it is not relevantly spotlighted in academic research in tourism. This fact is paradoxical given that the touristic phenomenon is the most important in terms of encounters among cultures. For that reason, in order to subsidize a discussion, this paper was divided into three sections. In the first section I outlined general contextualization and presented the methods utilized to perform this work. In the second part I approached ethnocentrism from its inception and, in a second moment, correlated to tourism. In the last stage, I narrated and correlated the three interviews in order to demonstrate how the ethnocentric discourse is not capable of logically sustaining itself and finally I exposed the conclusions as well as the references utilized in this work. Ideally, the encounter among cultures should promote awareness and cultural enrichment and a subject such as ethnocentrism should be widely discussed in all instances of the touristic field, but above all in the academic field. Furthermore, to promote awareness, education and motivate efforts towards cultural relativism is not just a matter of ethics or a convenient choice, but a logical necessity in a globalized context in which we, inevitably, find ourselves.
\end{abstract}

Keywords: ethnocentric discourse, international tourism, qualitative research, cultural relativism. 


\section{Introduction}

Ethnocentrism, according to Rocha [1] is a worldview in which one's own group is considered the center and other groups are thought and sensed through one's values, models and definitions of existence. On the intellectual level, it is classified as the difficulty to understand cultural differences while on the affective level, it is perceived by a sense of strangeness, fear, hostility, etc. This phenomenon, composed of these two elements, feeling and thinking, is deeply rooted in the existence, history and in many aspects of every individual's life. However, this approach is potentially problematic since as never before we interact with news, arts, products, services but most importantly with people from all over the world. The matter assumes greater importance when the result of the contact among cultures is based on misunderstandings evolving into conflicts instead of "an attitude of tolerance and respect for the diversity" [2].

Daily, thousands of people from different cultural backgrounds interact around the world in a context of international tourism. Although tourism, in terms of leisure, presupposes seeking for "the new", the travel itself, is likely to be framed from its inception in an ethnocentric imagery that corresponds solely to the traveler's view and not necessarily to the reality of the destination.

From the anthropological point of view, the feeling of strangeness allow individuals a better understanding of the self. Nevertheless, understanding the "other" and its culture from a blur perspective, limits our understanding about the diversity of human life [3]. In the social sciences, especially in anthropology, this way of interpreting the "other" has been strongly criticized and overcome, but in the common sense it persists to create cultural misfortunes, reinforcing the idea of cultural superiority. Several studies covered anthropological issues and its correspondence to tourism, emphasizing conflicts and behaviors. However, ethnocentrism is not an issue that stands out in the studies consulted. Hence the aim of this paper is to address a discussion regarding ethnocentrism as a determining factor in the context of international tourism. The methods used were bibliographical review and in-depth interviews.

\section{Methods}

This was an exploratory study and in order to foster a discussion about an ethnocentric discourse in the context of international tourism, literature reviews as well as interviews were conducted. The literature review covered books, dissertations, journal articles and online portals. The subjects explored were: the origin and context in which anthropology emerged, evolutionary anthropology, ethnocentrism, cultural and social anthropology, cultural relativism, tourism and anthropology, intercultural behavior in tourism, tourism and cultural conflicts.

As per the methodological purpose of the interviews in the context of social research, as Marconi and Lakartos [4] clarify that it:

"is a meeting between two people, so that one of them gets information about a certain subject, by means of a professional information about a 
certain subject, by means of a professional nature conversation. It is a procedure used in social research, to collect data to help in the diagnosis or treatment of a social problem."

The three interviewees were not randomly selected, characterizing a nonprobabilistic sampling. The interviews happened on different days in December of 2015 in a coffee shop and lasted for approximately one hour and half. The interview's questionnaire included only open ended questions, as follows: What is your age?; What is your level of education?; How long have you lived outside your country?; How often do you travel overseas?; How often do you look for information before a trip, such as: customs, laws, ways of behaving, social interactions or even cultural curiosities. This was a basic script that varied according to the answers placed. The advantage of the type of the questionnaire adopted is the adaptability of the questions. In other words, when the respondent/interviewer does not understand, does not offer clarity to a question/answer, any doubts can be made clear immediately. As for disadvantages, some respondents gave many details and sometimes even dispersed the point of the question which extended the interview duration. The interviews were conducted in English, Italian and Portuguese. For that reason, before the start of the interviews two rules were set in order to avoid miscommunication, partiality or concerns in being honest: the first was that the identity of the respondents would not be revealed and the second was that the content of the questions/answers should be fully understood by both interviewer and interviewee.

The data obtained was treated qualitatively as individuals, their statements and the correlation with the theory studied subsidized this discussion.

\section{The roots of ethnocentrism}

The science of anthropology studies humanity, mankind and its characteristics in time and space. Within the discipline there are different areas, including cultural or social anthropology, which according to Marconi and Pressotto [5] is the broader field of the discipline. Cultural anthropology, according to the authors, studies man as a cultural being and investigates the different cultures, its origins, development, similarities and differences. The focus of cultural anthropology is therefore on the knowledge of human behavior acquired through learning in all dimensions.

The origin of the discipline according to Burns [6], refers to a period in which three main issues converged in Classical Western Society: colonialism, the missionary societies and Darwinism. Colonialism represented Europe's technological advances and its "superiority" in face of non-European and hence "primitive" cultures. In the same vein, the missionaries had the mission to evangelize and "civilize" these "primitives", that is, they played a complementary role in colonization. Darwinism in turn refers to the misunderstanding of evolutionary theory of Darwin, which somehow justified both actions (colonialism and catechism). The interpretation indicated that 
biological evolution was unilinear and only the fittest survived. When such interpretation was applied to man, it characterized the idea of a cultural evolution. The blossoming of anthropology as a new discipline was in the above context, brought "with it an avalanche of moral and jocose judgments condemning barbarism, mirrored, of course, to the European superiority - a judgment that was capable of the most filthy racism in the face of the earth" [7].

In this context evolutionary anthropology emerged, with the idea that all cultures advance unilaterally from "savagery (hunting and gathering) to barbarism (grazing and agriculture) and finally to industrial civilization" [6]. Evolutionists "separated the facts from the contexts where they came from [...] compared behaviors, rather than comparing like we do today, the behavior inside its own context" [8]. Although in academia cultural evolutionism has been widely criticized as Massarani [9] elucidates, its influence follows in present branches of society.

\section{Tourism and ethnocentrism}

Tourism as Robinson [10] states "is arguably the largest of multinational activities" and its proportions can be recognized by the impressive data released by the United Nations World Tourism Organization [11].

After achieving an historic milestone in 2012 - of one billion people traveling the world in a single year - international tourism continued its momentum with a $5 \%$ growth in 2013 , or an additional 52 million international tourists, bringing up the world total to a record 1,087 million arrivals. Despite the ongoing global economic challenges and geopolitical changes, international tourism results were above expectations and long term forecasts.

The economic benefits of tourism to entire cities, regions and countries justify its attractiveness as well as the tone of commemoration of the UNWTO towards the expressive numbers.

In order to define tourism, several authors and institutions have approached it mostly from the perspective of their fields of study. For this reason, there is a certain plurality when it comes to its definitions. Although there is a consensus regarding the complexity of the subject, as it includes directly and indirectly a multidisciplinary and diverse range of positive and negative issues related to sectors, actors, spaces, etc. In this paper we highlight Barretto's [12] definition:

Tourism is the movement of people who, for various reasons temporarily leave their place of residence, aiming elsewhere, using a series of equipment and services specially deployed for this type of visitation. The activity of tourists happens during displacement and stay outside their home. Touristic businesses are conducted with equipment or with the provision of services that tourists use in the preparation and execution of the activity. They start at the origin, when tourists flock to a travel agency or a transport company to buy a tour package or a ticket, still when 
tourists arrive at the place of destination and use local transport, accommodation, food services, amusement network, souvenir shops, etc. and even when they return home and take their pictures to get developed in their neighborhood store.

According to this definition the effects of the tourism industry have a starting point that is not solely related to the destiny or from the moment of displacement but from the moment of purchase of the travel. Likewise, the author mentions that the industry's effects proceed when the pictures are taken to the neighborhood shop to be developed. Both ideas are intrinsic economic effects of the industry. However, it is reasonable to take into account the effects of ethnocentrism in the touristic experience as a whole. For instance the tourist's imaginary of a destination can be totally based in an ethnocentric view that does not correspond to the reality. Similarly, when tourists return home, comments can be based in ethnocentric, racist or stereotyped views.

\section{The ethnocentric discourse in the context of international travel}

Nelly is from Malaysia and has traveled to more than 20 countries. She has also lived in Australia, United Kingdom and in South Korea. She holds a Master's degree in information technology and currently owns a recruiting company in Malaysia which she manages from a distance. She has lived abroad for 3 years and most of her travels are for leisure which is defined by Dumazedier [13] as

a number of occupations in which the individual may indulge of his own free will - either to rest, to amuse himself, to add to his knowledge or improve his skills disinterestedly or to increase his voluntary participation in the life of the community after discharging his professional, family and social duties.

In the first half of 2015 Nelly visited Helsinki and in the second half she traveled to Italy, visiting Rome, Florence and Venice. When asked if she had experienced an uncomfortable situation due to miscommunication or cultural differences with people from other countries, or a positive or negative surprise, culture shock, she answered with emphasis:

Undoubtedly, many. The first culture shock I had was when I first went to Europe. In Europe it seems that everything, everything is possible. That was a shock to me, because in my culture, we are more restrained and traditional. We have different values. We Asians have many similarities, but there are many problems that are caused by cultural issues, such as the problems that we see in Korean culture, for example.

Rocha [1] explains that culture shock happens within the context of ethnocentrism: 
On the one hand we know that "our" group eats the same kind of food, dresses the same way, likes similar things, knows problems of the same kind, believes in the same gods, marries the same way, lives in the same style, distributes power and shares life's meanings in the same way [...]. And, then, we meet the group of "other" that sometimes do not even do things like we do it is in a certain way that we do not recognize as possible. [...] This shock that causes ethnocentrism to be born, perhaps, when differences are perceived.

When asked what problems Koreans faced, the respondent mentioned: "Koreans did not evolve. They live in a tradition that can no longer be held".

As mentioned earlier, the first assumption in an ethnocentric discourse is that the culture of the other has not evolved or is inferior to the person that is analyzing it. Since Nelly mentioned cultural aspects regarding South Korea, the interview was focused on conflicting issues, for example the fact that Koreans eat dogs: "They (Koreans) should be forbidden to eat dog meat. They have so many choices of meat. Why should they eat dog? Dogs are considered pets nowadays and by the way there is not even a considerable quantity of meat in dogs." After that, it was asked whether dogs or chicken had more meat the respondent answered "You cannot compare a dog with a chicken".

And finally, when asked whether she knows the reason why Koreans eat dogs, she replied negatively.

The fact that Koreans eat dogs dates back hundreds, or even thousands of years and has very deep cultural implications. Only to confront what the interviewee puts in discussion, the illustration (Figure 1) below of Pawel Kuczynski [14] implies that domestication of some animals rather than others is just a contradictory fact that cannot be easily justified.

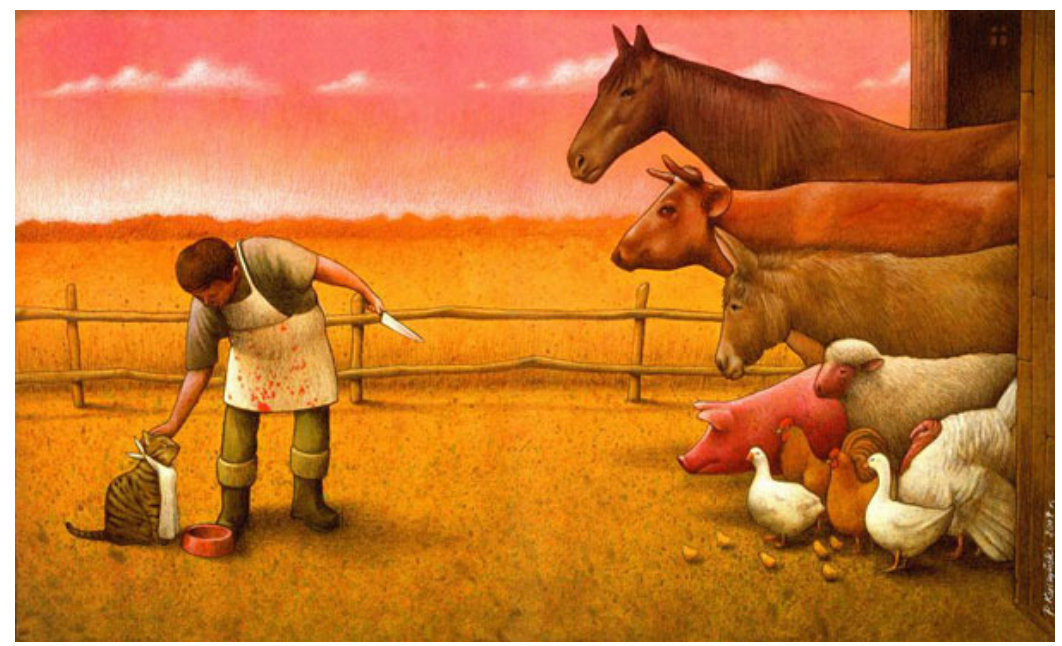

Figure 1: What is the difference among us? 
When the question regarding the similarities between Korea and Malaysia when it comes to social hierarchy in which younger people should respect extremely older people (for instance Malaysian Hindu) Nelly replied:

In my country it is a priority to respect the elders, but we need to ask ourselves about these issues. In Malaysia, people are giving respect if they are given respect. Here in Korea the elders commit several abuses because of this tradition. It's something that undoubtedly needs to change. It is necessary to question the traditions.

As mentioned above, according to the interviewee, the way Malaysians interpret and deal with the situation is superior to the way Koreans do. Nelly was also asked about other issues that are usually the grounds for complaints among foreigners living in Korea, such as the fact that Koreans stumble into people and do not excuse themselves or the fact that Koreans jump the queue, spit on the floor in public and other situations: "They did not evolve in that sense. They think you're invisible. But one day they will learn because the youth is already learning to behave."

What is implicit in this speech is that there is a way to behave, and this way is to be learned by Koreans. This is one more feature of the idea of evolutionary anthropology the main premise of which is that evolution occurs in a single direction. During the interview, Nelly made sure to specify positive characteristics of Koreans, "they are very loyal. They are not racist. They are really genuine."

In regards to the contact among people of different cultural backgrounds Reisinger and Turner [15] highlight that "it may result in positive as well as negative outcomes". Nevertheless, ethnocentrism is so complex that even a positive interaction may be based on perceptions that do not relativize the existence of the other. Rocha [1] exemplifies this idea as follows: "[...] the other can be angry and treacherous as well as docile and kind."

In that vein, Nelly's positive perception of Koreans was contradicted by Sara, the second interviewee. In her opinion, Koreans are "racists, unless you have lots of money". And she continues: "Koreans have a weird way to behave. Sometimes they do not look normal to me."

Sara is Italian and before moving to South Korea four years ago, the only country where she lived besides Italy, she was a teacher. Sara traveled to more than thirty countries and last trip abroad was to Thailand. When the question was whether she had ever witnessed, experienced or was surprised positively or negatively by a type of behavior while traveling:

Yes, very often. [...] When I went to China, I was waiting for a bus and I made the gesture for him to stop. He stopped away from me and when I got to the door, he closed it and almost hit my face. The driver simply started up the bus, looked at me and started to laugh and people who were on the bus also started laughing too. It was a horrible day. 
When asked why the driver had done that, the interviewee said, "of course it was because I was a foreigner. I do not think they would have done the same with a Chinese". According to Barretto [12], "although it is not common to witness xenophobia against tourists by service providers, often it is presented as a disregard, negligence or a service grudgingly". The interviewee continued her answers:

The Chinese have much to learn. But I mean in many ways. They take nose poop in front of everyone, they spit on the ground frequently, they eat insects, cockroaches, scorpions, and they have complete different notions of hygiene. It is for this reason that the Chinese government is teaching people how to behave, to speak English correctly, etc.

But when it comes to the same statement, Korean Yoon also has contradictory thoughts:

I went to Italy last year and people stressed me throughout. I first tried to buy a cappuccino, I had already paid and asked for a cappuccino at the cashier. In Korea, we order at the cashier and the order will automatically be sent to the barista and as soon as possible prepared. I was waiting a few minutes and no one told me anything. Then when I saw that everyone gave the receipt to the barista I gave mine and asked for my cappuccino. The barista was talking to other people and was slow. If he were in Korea he would have been fired the same day. Italians are very slow.

Yoon is an engineer who lived in Brazil for three years and traveled as a tourist to more than fifteen countries. Another interesting issue was food: "Korean food is not only tastier but healthier". Furthermore, when asked about Italian food, he said: "The Korean pizza is much better".

With regards to Korean food, Sara, mentions that she had to get used to "the filthy Korean Food" as she cannot always cook Italian food because it is not possible to find "good ingredients" in Korea.

\section{Conclusions}

The interviews expressed how the ethnocentric discourse differentiates the other in a level of progress and superiority. For the group of "I" there is always a need for the "other" to evolve, learn and change. It is extremely important to understand our value and what constitutes us as individuals and groups. However, in the same way we legitimize our characteristics as a group and expect them to be respected, we must ensure that the characteristics of the "other" are likewise respected. In this regard, Yázigi's [7] statement is relevant to think the importance of respecting the difference: "If the I should take priority over objectivity, any holocaust then becomes legitimate".

Several authors $[6,10,15,16]$ refer to the encounter between tourist and resident and/or agent of tourism as ephemeral. However many times, although 
short, it is long enough to enhance stereotypes or generate irreparable conflicts that can be of catastrophic proportions.

This paper's aim is not to argue that tourists in general are engaging and understanding the touristic experience solely from an ethnocentric point of view. In reality, as Barretto [16] elucidates, there are numerous types of tourists who differ socially, economically and have different motivations when undertaking the touristic experience.

The ethnocentric approach can occur in many forms at any stage of the journey. It reasonable to assume that although some tourists will return home with ethnocentric point of views, other will demystify preconceptions, stereotypes, and will understand that the actions of the "other" have a sense inside its own context.

It is rationally inconsistent for a tourist to assess the "other" or expecting him to evolve and react like himself since the travel itself is precisely motivated by diversity. In the same vein, this paper does not aim to imply that the meeting between cultures should annul the understanding of the group of "I". Nevertheless, it would be unconceivable that a tourist (who does not share the same history, religion, principles or values etc.) enter the house of the "other", in this case the country, and affirm that his attitudes are inappropriate, that he must learn how to behave, change and evolve.

Furthermore, this paper does not imply that the tourist has no right to be critical regarding the other's culture. However, what cultural enrichment do we obtain with a travel when the other is solely interpreted by our own parameters?

Tourism is/should be a great possibility in terms of learning and discovering the most variety of dimensions of existence, characteristics and spaces.

Finally, to relativize difference is not just a matter of mere understanding and respect between cultures, but an ethical issue that should be aspired and discussed by all actors related to tourism.

Professor Bennett [17], explains that the first viable solution that human beings tend to choose in front of difference is to "eliminate the culturally different people." According to him, a way out of ideas like these is an intercultural education around the world, seems to be in the long term the best solution. Intercultural communication and other issues such as ethnocentrism are the basics in the intent to effectively create understanding among peoples.

\section{References}

[1] Rocha, E. P. G. What is ethnocentrism. São Paulo: Brasiliense, pp. 5-14, 1988.

[2] UNWTO. The global code of ethics for tourism. http://www.gdrc.org/ uem/eco-tour/principles.html

[3] Ribeiro, P. S. Ethnocentrism http://www.brasilescola.com/sociologia/ etnocentrismo.html

[4] Marconi, M. A; Lakatos, E. M. Scientific Methodology Fundamentals. 7. ed. São Paulo: Atlas S. A., p. 178, 2010. 
[5] Marconi, M. A.; Pressotto, Z. M. N. An introduction to Anthropology. 7. Ed. - 4. Reimpr. - São Paulo: Atlas, pp. 5-7, 2011.

[6] Burns, P. An introduction to Tourism and Anthropology. São Paulo: Chronos, 2002. Campinas: Papirus, pp. 21-22, 2001.

[7] Yázigi, E. A.. A. Methodological adjustments: cultural relativism and tourism. (Part 2) The Panorama of the Brazilian Geography. Silva, J. B.C.; Lima, L. C.; Elias S, D. (Orgs.). São Paulo: AnnaBlume, v. 1, pp. 131136, 2006.

[8] Da Matta, R. Relativizing: An Introduction to Social Anthropology. Rio de Janeiro: Rocco, p. 90, 1991.

[9] Massarani, S. Evolve to win - Evolutionary theory of anthropology in civilization games. http://www.massarani.com.br/files/Evolucionismo Civilization.pdf

[10] Robinson, M. Cultural Conflicts in Tourism: Inevitability and Inequality. In: Robinson, M. \& P. Boniface (Orgs.). Tourism and cultural conflicts. CABI Rocco, p. 1, 1999.

[11] World Tourism Organization, UNWTO. Annual Report 2013, UNWTO, Madrid, 2014. http://www2.unwto.org/annual-reports

[12] Barretto, M. The essential contribution of social sciences for planning and understanding tourism. Horizontes Antropológicos 20(9), pp. 15-29, 2003.

[13] Dumazedier, J. Sociology of Leisure. São Paulo: Perspectiva, p. 25, 1999.

[14] Pêsega. D'oro - Pawel Kuczynski e suas ilustrações recheadas de sátiras sociais e políticas. http:/www.pessegadoro.com/2012/08/pawel-kuczynski -e-suas-ilustracoes.html

[15] Reisinger, Y., Turner, L. W. Cross-cultural Behavior in Tourism: Concepts and Analysis. Oxford: Butter-Heinemann, p. 39, 2003.

[16] Barretto, Margarita. Relations between visitors and visited: a retrospective of socio-anthropological studies. In: Tourism in analysis 15 (2). São Paulo: Aleph Editora e Eca USP, 2004.

[17] Interculturalidade. Você sabe o que é? http://revistaepoca.globo.com/ Revista/Epoca/0,EMI250960-15228,00-INTERCULTURALIDADE+ $\mathrm{VOCE}+\mathrm{SABE}+\mathrm{O}+\mathrm{QUE}+\mathrm{E} . \mathrm{html}$ 